\title{
REPORT ON LEPROSY IN THE UNION OF SOUTH AFRICA
}

\section{INTKODUC'TION}

On behalf of the British Empire Leprosy Relief Association and at the invitation of the Department of Public Health, I visited the Union of South Africa during part of July and August, I939, and studied leprosy and the methods adopted for its relief and control at the four principal leper settlements: Pretoria, Emjanyana, Mkambati and Amatikulu.

As requested by the Secretary for Public Health I embody in the form of a report my impressions.

I shall describe shortly some of the main features and comment on particular matters concerning each of the four institutions, and then deal with more general matters.

\section{LEPER INSTITUTIONS}

West Fort Leper Institution, Pretoria. This is situated some seven miles to the west of Pretoria. The staff consists of a Medical Superintendent and three other medical officers, a female nursing staff of 28 , Io overseers (male nurses), 3 storekeepers, 4 office staff and 5 others.

The estimated running cost to Government in I939 was $£ 23,004$ for staff and $£ 2$ I, ooo for supplies. It housed on June 30 th, I938, 95 Euröpeans, 68I Natives, 90 Mixed Coloured and 7 Asiatic.

The disease appears to be of a severer form among the Europeans than among the Natives. Every one of the twelve Europeans admitted during the last twelve months was of the severe lepromatous type, while of the Natives admitted during the same period only twenty-five per cent. were lepromatous, the remainder being of the milder neural type more likely to recover. The reasons underlying this severity of type among Europeans are worthy of careful investigation. All contacts of lepers admitted are examined periodically, and it is not likely that the difference between the two classes of patients could be due to milder cases among Europeans escaping detection. Malnutrition is common to both classes of patients, so this could not account for the difference. There are two possible explanations which present themselves :-

(r) That contacts are less close among Europeans and that therefore only the minority of susceptibles in the European community acquire the disease and that in the severe form, whereas contacts are so close and so frequent among Natives that even non-susceptibles acquire leprosy though only in the milder form; and (2) that climatically the European is at a disadvantage in South Africa as regards leprosy, or that the disease produces in him more mental and consequently more physical depression, 
and in this way lowers his resistance. The question of racial resistance to leprosy is a most important one and the contrast between these two communities at West Fort offers a unique opportunity for its study.

In spite of the severer type, the total number of European lepers has for some years been steadily decreasing and is now only about half what it was twenty years ago. This is no doubt chiefly due to segregation of infectious cases.

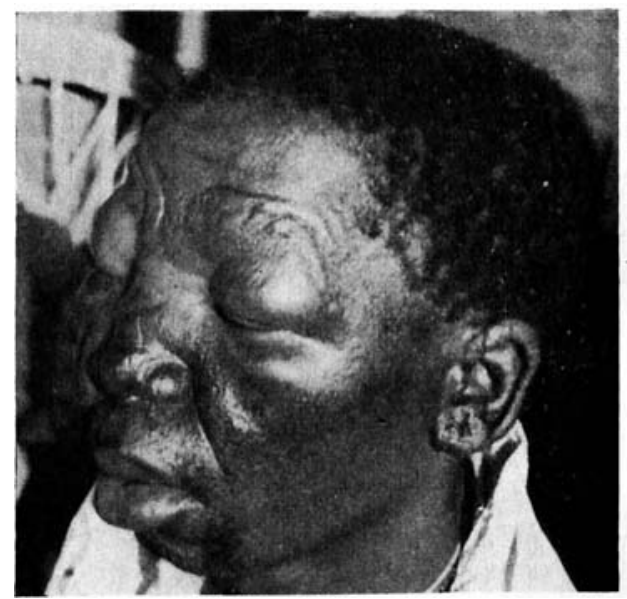

FIG. 8.

Pretoria Institution: febrile reaction with swelling of face in lepromatous case.

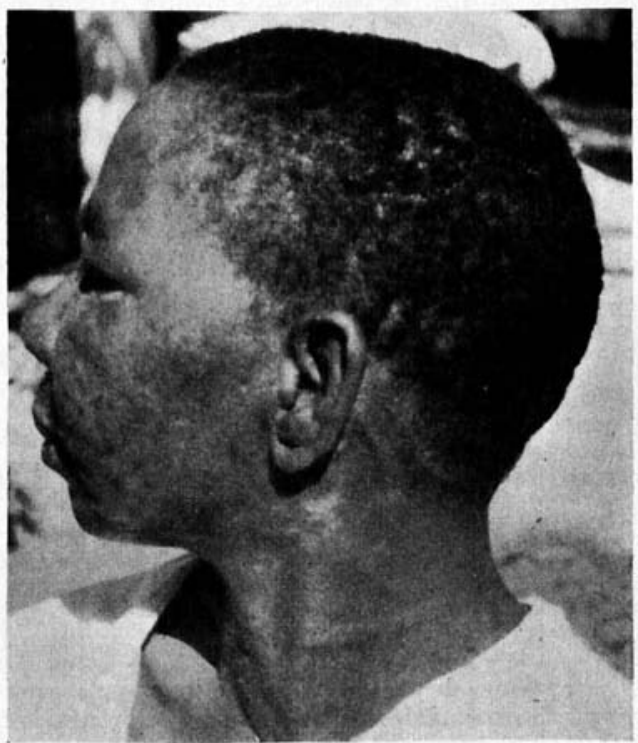

FIG. 9.

PRETORIA : reacting major tuberculoid lesion of face; notice clear-cut margin and thickened cervical nerves. 
Outside America there are few leprosy institutions in the world where so much is spent by the State on each patient. For treatment, nursing and catering, the staff and supplies are adequate.

Besides the differences of types in European and Native patients there are two other features which I noted as peculiar to or at least particularly common in this institution :-

(r) Several patients were seen with scars of old tuberculoid lesions who had later developed lepromatous lesions (Leprosy' Review, October, I.939, P.225); some of them had undergone a similar deterioration after admission to the institution, as shown by comparing past records with the present condition. (2) Several lepromatous cases with nodules of the face and widespread diffuse lesions of the body develop sudden swelling and oedema of the lesions of the face but not of the body. This is accompanied by a rise of temperature. This condition resembles the condition known as "lepra reaction," so common in India and elsewhere, but comparatively uncommon in East, Central and South Central Africa (fig. 8).

All these peculiarities offer problems for investigation; I would suggest that the possible connection with lack of sufficient physical exercise be looked into, as this lack is one of the most apparent differences between West Fort and most of the institutions in the parts mentioned above (see also p.47).

Emjanyana Leper Institution is situated in the Transkei. It has a staff of 22 Europeans and 88 natives, and an annual expenditure of $£ 24,898$. On the 3oth June, 1938, there were 665 patients, all natives. This institution has a distinct advantage over West Fort in that all the inmates are from native tribes and most of them from tribes in the Transkei, though patients are also admitted from the Cape Province. The Superintendent, who has been in charge for twenty years, studied the customs of the people and planned the present form of the institution upon these customs. In consequence, law and order are maintained through native headmen and by the patients themselves. The settlement is divided into two main camps, male and female, more than one mile apart; the females are not allowed to wander from their enclosure except in groups, which is in accord with native custom.

There is a creche for children born of newly admitted patients or children brought in with their leprous mothers; they are looked after in the creche till the mother is discharged, or till the child can take ordinary food and be handed over to relatives. The creche is in the female compound and mothers are allowed to see but not to come in contact with their children.

There is a farm and a vegetable garden, each under European supervision; from these meat, milk, mealies, vegetables, etc. are supplied to the patients.

I had an opportunity of examining and discussing a number of cases with Dr. Willmot and Dr. le Roux, members of the 
Leprosy Board, and Dr. van der Lith, the Medical Officer. About three-quarters of the patients admitted are of the neural type, most of them with tuberculoid lesions, only one-quarter being lepromatous. This proportion is similar to that of the Native patients admitted at West Fort. In the year ending 3oth June, 1938, one hundred and seventy-two patients were discharged, almost all being from among the neural type. Large as this number is, possibly even more could be discharged if trophic ulcers were operated on and dead bone removed. So far patients have objected to such operations, but with patience and persuasion this objection should be removed. It is worthy of note that about 4I per cent. of discharges last year were from this institution which contained only 29 per cent. of the segregated patients. This may be partly due to the fact that the patients themselves insisted on compulsory treatment. I think it might be possible to get better results with lepromatous cases if the treatment of suitable cases was regulated with the help of the sedimentation test, and if sufficient healthy exercise could be arranged for all who are fit for it. At present only about one-third of the male patients have regular employment and it has been noticed that those so employed make better progress than the others.

The system adopted at Emjanyana has taken the sting out of compulsion. The place is so popular that more than a third of the patients come in of their own accord, and the others make no difficulty when told to go to a depot or other place where they are collected and brought in by the settlement's motor ambulance.

Mkambati Leper Institution. This institution is situated in 90.square miles of ranch land bordering on the shore of Pondoland. The ranch supplies meat and milk to the patients and staff. The institution is under a resident Superintendent, and the medical and nursing staff is supplied by the Holy Cross Mission some 30 miles distant, Dr. Drew visiting from there and the three European sisters being in residence.

There are about 200 patients of which, as in other institutions, the majority are of the neural type.

The most striking feature of the Mkambati Settlement as compared with others is the almost complete absence of patients with trophic ulcers. This is due to four chief measures :-

(I) Prompt operations on the feet of patients and removal when necessary of sufficient bone. This method has also been followed in several of the principal Indian institutions.

(2) The patients wash thoroughly in soap and water daily and then rub oil on themselves and on each other. Separate enclosures fitted with shower baths are provided for men and women.

(3) Patients are taught to take care of their teeth; they are given a mixture of $\mathrm{Tr}$. Ipecac., Peroxide of Hydrogen, Liquor arsenicalis and 
Glycerine (equal parts) to rub on the teeth and gums. Noses are douched with $I$ in 150 Dettol and sprayed with S.T.37 ( 1 in 3 solution).

(4) There are communai exercises such as Indian clubs and massage, and special exercises are used to prevent deformities of the hand.

All accompanying diseases are treated and an endeavour is made to regulate special treatment according to the general condition of the patient. As in most institutions where individual, as opposed to mass, treatment is given, the sedimentation test is used in judging the general resistance of the patient and his tolerance of special drugs.

As in other institutions in the Union, sufficient bacteriological examinations of the skin do not appear to be used in determining the type and condition of the patient and in regulating the treatment. I consider it highly important that there should be a well equipped clinical laboratory and an African laboratory assistant, without which it is impossible adequately to carry out these examinations and also such essential examinations as the Sedimentation and Kahn tests.

The children born in the institution are brought up successfully in a crèche. As elsewhere it is found that unless they are kept in the crèche till they are three years old they are unlikely to survive when handed over to outside relatives.

The large proportion of patients discharged (see table on p.5I) is worthy of note.

Amatikulu Leper Instituation. The Amatikulu Leper Institution is situated in Zululand near the coast and some I4 miles north of the Tugela River. There is a European staff of seven, including the Superintendent and Matron. The part-time medical officer visits the institution four times a week. Under the Matron the nursing is carried on by trained African male and female nurses.

There is a large stock farm connected with the institution which supplies milk and meat to the patients.

There are hospital wards for the male and female patients. The most of the patients are housed in round huts of the native type; but these are gradually being replaced with brick and cement houses.

There are $\mathbf{4 7 2}$ patients, of whom 103 were passed for discharge by the Leprosy Board as arrested cases on the day of my visit. This is a large proportion, and speaks well for the efficacy of the treatment. Of the 136 patients admitted in the last twelve months only 20 were of the lepromatous (severe) type, an even smaller proportion than in the other institutions. The large number of admissions and discharges shows the popularity of this settlement. 
The patients appear to be happy and contented, and no fences or other restrictions are necessary to keep them from absconding.

While the numbers of the Mkambati Institution are diminishing, apparently due in large measure to the elimination of leprosy from Pondoland, the numbers at Amatikulu are tending to increase; this maty be attributed to the fact that this institution is now attracting patients from long-existing foci which hitherto have not been reached.

I had an opportunity of examining, along with members of the Leprosy Board and the visiting physician, a number of the patients. They appear to be types very similar to those in the other institutions. I was informed that cases of "lepra reaction" are not infrequent, especially in tne winter. in these tne face and sometimes the limbs become suddenly swollen and congested and there are febrile symptoms. This state is found only in the lepromatous type (fig. 6). There is a large proportion of patients with trophic conditions which might be cleared up by operation.

\section{General Remakks}

Comprulsiry Sigregation. The system of leprosy control in the Union of South Africa differs from that in most other British Territories in that it is compulsory. In consequence it has been necessary to spend far more money than elsewhere. In I9I8 the estimates for leprosy were $£_{118,000}$ and in 1939, $£_{125,596}$, as shown in the following table :-

Pretoria Leper Institution

Emjanyana Leper Institution

Amatikulu Leper Institution

Bochem Leper Institution

Mkambati Leper Institution

\begin{tabular}{|c|c|c|}
\hline European Staff & $55)$ & \\
\hline Native Staff ... & $72)$ & $£ 23,004$ \\
\hline Supplies & & $2 \mathrm{I}, 000$ \\
\hline European Staff & $22)$ & \\
\hline Native Staff ... & $88)$ & 12,948 \\
\hline Supplies & & $12,95^{\circ}$ \\
\hline European Staff & $8)$ & \\
\hline Native Staff ... & $57)$ & 6,417 \\
\hline Supplies $\quad \ldots$ & & 5,300 \\
\hline European Staff & I & \\
\hline Native Staff ... & $6)$ & 1,032 \\
\hline Supplies $\quad \ldots$ & & $I, 750$ \\
\hline European Staff & & \\
\hline Native Staff ... & 65 & 5,195 \\
\hline Supplies $\quad \ldots$ & & 5,000 \\
\hline
\end{tabular}

20,000

Maintenance outside institutions of indigent patients and their dependants

Transport of patients and their relatives to and from institutions

Contingencies and Union Leprosy Board and Advisory Committee

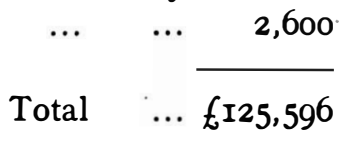

8,400

2,600

Total $\quad \cdots £ 125,596$

These figures do not include capital expenditure. In I9I8 
there were 2,374 patients in the various institutions and 20 years later there were 2,265. Though the number of lepers in the institutions does not appear to have decreased greatly, it can be stated with some degree of certainty that the number of lepers outside has decreased considerably during this period. On June 3oth, 1938, there were 1,764 patients who had been discharged but were still under surveillance, and 2,738 others had already been released from surveillance. As is mentioned above, there is now only about half the number of European patients segregated that there was 20 years ago; and, while the number of native cases still at large cannot be accurately stated, there is no doubt that improved treatment, improved transport and improved medical services in the districts have accelerated the turn-over of patients.

As shown above, an almost entirely voluntary system obtains at Emjanyana, and it is unfortunate that the lack of tribal cohesion at West Fort has so far made it impossible to organise a similar system there. On this account it is the more urgent that the social life of the Native patients at West Fort should be organised, so that the sting of compulsion may as far as possible be removed.

A compulsory system similar to that in the Union would necessarily be impossible in other British Territories in Africa, if for no other reason, on account of expense. The Union spends between $£ 40$ and $£ 50$ a year on each of its segregated lepers. A corresponding expenditure in Nigeria would cost many millions a year. There, the chief hope of controlling leprosy is through educating the people in the danger of infection and how it can be avoided, and thus gradually bringing about segregation through compulsion applied by the community itself.

In the Union, the degree and nature of compulsion has been determined largely by the resistance of certain classes of lepers to voluntary segregation and by the importance which the community sets upon the removal of sources of infection. It has also been determined by the ability and willingness of the community to pay the price. There seems little doubt that if the present system is persisted with it will succeed in the end.

Treatment in the Leper Institutions. I would suggest that more emphasis be laid on developing physical culture among the patients, and consider that this would result in better results, especially in those with the severe type of the disease who at present seldom recover or are discharged from the institutions. Also in treating cases of this type I would strongly advocate the use of the sedimentation test.

At present iodised esters of hydnocarpus oil are used. In place of this the equally beneficial oil itself as supplied by a reliable 
Indian firm might be used. Iodised esters when injected intradermally blacken the skin and make it difficult to determine the degree of improvement in tuberculoid lesions. The oil is cheaper and is more stable and less likely to become irritant, especially if 4 per cent creosote is added. The disadvantage of its greater viscosity can be overcome by injecting it hot (Leprosy Review, July, I939, p.I86).

Intradermal injections tend to accelerate the clearing up of tuberculoid lesions; each lesion should be injected in turn and reinjected at an interval of not less than a month, this being repeated until all active signs have disappeared. If there are too few lesions to supply injection sites for a month, intramuscular injections may be given in the intervals. It is well to inject at least half an inch beyond the margin of a macule, as the infection has generally spread beyond the apparent edge.

The treatment of trophic ulcers, especially those of the feet, is a most important matter. I have referred above to the almost complete absence of trophic ulcers at Mkambati. This is in marked contrast to the other institutions. Trophic ulcers of the feet are generally associated with decalcification and necrosis of the bones, especially of the metacarpal and phalangeal bones. When less radical measures fail to cause prompt and permanent healing of trophic ulcers, it is important that without delay dead and diseased bone be removed by operation. If this is not done the patient soon becomes a chronic invalid, he absorbs toxins from his septic sores, he is immobilised and his muscles become soft and flabby; in consequence his leprosy becomes worse and his chance of recovery without serious deformity and disfigurement soon disappears. Anyone wishing proof of the importance of immediate operation, and of the other measures for keeping the patient strong and active, has only to visit the Mkambati Institution.

Educational Campaign. Leprosy is likely to be completely eradicated only when the classes among whom it exists have learned the dangers of leprosy and how they may be avoided. With this end in view a small illustrated pamphlet, entitled " Control of Leprosy' has been prepared by the British Empire Leprosy Relief Association and widely distributed by the Medical Departments throughout Africa, especially to those who are responsible for administration and education. It has been translated into four of the principal African vernaculars. I would suggest that this be used in educating the public regarding leprosy.

Examining Patients. At present great stress is laid upon positive bacteriological examination of material taken with a swab 
from the nose. In my experience mistakes are sometimes made by confusing partially acid-fast saprophytes such as the smegma bacilli, frequently present in the nose, with lepra bacilli. For making a smear it is better to gouge out a small piece of mucous membrane with a sharp knife. Before each examination the knife should be carefully flamed, as wiping and boiling do not always remove all the acid-fast bacilli gathered from the last case.

The nose is seldom positive without the skin also being positive, though the reverse is scarcely true; and I would suggest that the chief reliance be laid on a positive skin finding, either from an obvious skin lesion such as nodule or plaque, or from the lobule of the ear. When repeated examinations of skin lesions are negative the nasal mucous membrane should also be examined by the method mentioned above.

The diagnosis, and especially the clinical diagnosis, of leprosy are often exceedingly difficult for doctors who have not had adequate opportunities of studying all types of cases under an expert. I would suggest that increased facilities be given to district surgeons to undergo such study at one or other of the leprosy institutions.

Standards for discharge of patients. Neural cases with less extensive lesions and with good physique will as a rule heal up rapidly under intradermal injections, and the restrictions of repeated bacteriological examinations necessary for lepromatous cases need not be applied.

For lepromatous cases in good general health, who have reached the stage of becoming repeatedly bacteriologically negative, I would suggest the careful application of the iodide test (see Leprosy Diagnosis, Treatment and Prevention, 6th Edition). 'No pronouncement of negative findings should be given on any one occasion till several skin (from different parts of the body) and nose smears have been examined carefully. Without these strict rules relapses are more liable to occur.

The following two tables give the number of patients in the institutions on June 30th, 1938, and the admissions, discharges, etc. for the year ending June 3oth, I938 :-

\begin{tabular}{|c|c|c|c|c|c|c|c|c|c|}
\hline Institution & $\begin{array}{l}\text { Euro } \\
\mathbf{M} .\end{array}$ & $\begin{array}{l}\text { peans } \\
\mathrm{F} \text {. }\end{array}$ & $\begin{array}{l}\text { Native } \\
\text { M. F. }\end{array}$ & $\begin{array}{l}\text { Mix } \\
\text { Colo } \\
\text { M. }\end{array}$ & & $\begin{array}{c}\text { Asiatic } \\
\text { M. F }\end{array}$ & M. & & al \\
\hline Pretoria & 64 & $3 I$ & $455 \quad 226$ & 57 & 32 & 34 & 579 & 293 & 872 \\
\hline Mkambati & - & - & II $7 \quad 85$ & -- & - & -- & II 7 & 85 & 202 \\
\hline Imjanyana & - & - & 349316 & - & - & -- & 349 & 316 & 665 \\
\hline Amatikulu & - & - & 28I I67 & - . & - & -- & $28 \mathrm{I}$ & I67 & 448 \\
\hline Bochem & - & - & 32 & $\ldots$ & I & -- & 45 & 33 & 78 \\
\hline Total & 64 & $3 I$ & I247826 & 57 & 33 & 3 & I37I & 894 & 2265 \\
\hline
\end{tabular}




$\begin{array}{cccccc}\begin{array}{c}\text { Institution } \\ \text { Pretoria }\end{array} & \ldots & \text { Admission } & \text { Readmission as } & & \\ \text { for first time } & \text { recrudesced } & \text { Discharged } & \text { Died } \\ \text { Mkambati } & \ldots & 2 \text { I5 } & \text { I8 } & \text { I3I } & 97 \\ \text { Emjanyana } & \ldots & 44 & \text { II } & 66 & 24 \\ \text { Amatikulu } & \ldots & 255 & \text { I2 } & \text { I72 } & 84 \\ \text { Bochem } & \ldots & 93 & 26 & 35 & 4 \text { I } \\ \text { Totals } & \ldots & \text { I9 } & 4 & \text { II } & \text { II } \\ & 626 & 7 \text { I } & 4 \text { I } 5 & 257\end{array}$

Classification of Cases. The institutions in the Union have not yet adopted the method of classification recommended by the recent International Leprosy Congress at Cairo. Much research in leprosy is being done throughout the world, and the use of varying forms of nomenclature is bound to lead to confusion. I would therefore suggest that the use of the international classification would be an advantage both to workers in South Africa and to those outside the Union who seek to benefit by studying the valuable contributions made within the Union to the subject of leprosy

\section{Research AND Conference}

In the past many valuable contributions have been made to the subiect of leprosy by workers in South Africa. In my tour of the Union I have been struck by the wealth of material available and the strong desire of the doctors to undertake investigations into the many unsolved problems of leprosy. The best treatment is generally carried out by those who are themselves actively engaged in research. Such research, as well as the employment of such important tests as the Kahn and the Sedimentation, would be made possible or facilitated by providing suitable clinical laboratory equipment and African laboratory assistants.

Bacteriological examination should be counted as a part of clinical examination. The skin should be studied clinically with the aid of repeated bacteriological examinations, otherwise a wrong impression is apt to be gained from naked-eye appearance alone. It is therefore necessary for these examinations to be made on the spot.

One of the chief handicaps in the way of research and improved methods is the isolation in which the doctors of the leprosy institutions have to work. This could be remedied by holding yearly conferences in one or other of the leprosy institutions; at these leprosy workers in South Africa could meet, and leprologists from neighbouring countries, such as Southern Rhodesia, might be invited to attend. 